2

3

4

5

6

7

8

9

10

11

12

13

14

15

16

17

18

19

20

21

22

$23 *$ Correspondance to:

24 Sasho Gligorovski

25 gligorovski@gig.ac.cn

\section{Ionic Strength Effect Alters the Heterogeneous Ozone Oxidation of Methoxyphenols in Going from Cloud Droplets to Aerosol Deliquescent Particles}

Majda Mekic ${ }^{\ddagger 1,2}$, Yiqun Wang ${ }^{1,2}$, Gwendal Loisel $^{1}$, Davide Vione ${ }^{3}$, Sasho Gligorovski $^{{ }^{*}}$

${ }^{1}$ State Key Laboratory of Organic Geochemistry, Guangzhou Institute of Geochemistry, Chinese Academy of Sciences, Guangzhou 510 640, China ${ }^{2}$ University of Chinese Academy of Sciences, Beijing 10069, China

${ }^{3}$ Dipartimento di Chimica, Università degli Studi di Torino, Via Pietro Giuria 5, 10125 Torino, Italy 
Supplementary information contains 4 figures and 1 table.

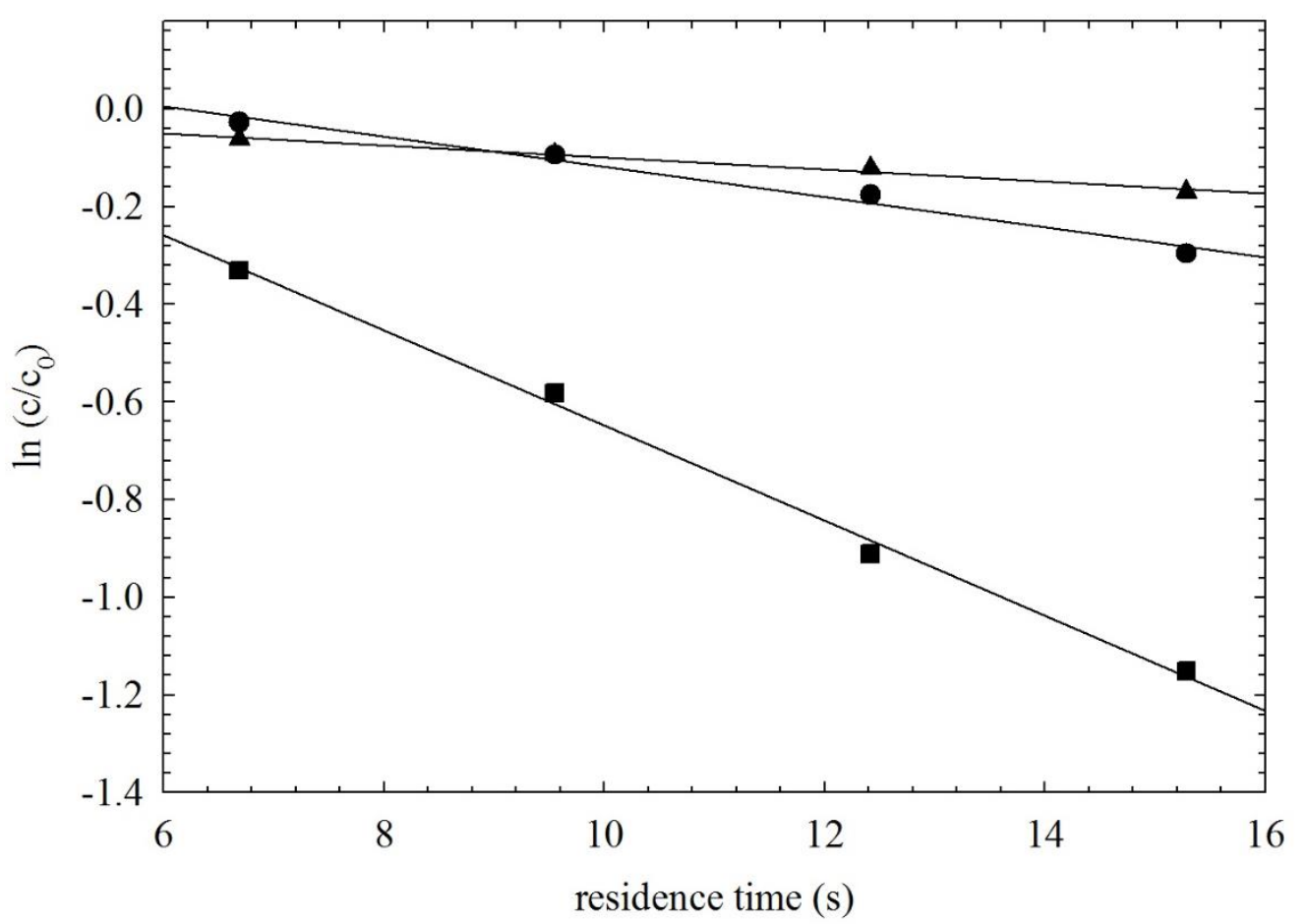

27

28

29

30

31

32

33

Figure S1: First order decays of ozone as a function of residence time under dark conditions, in the presence of: $\bullet$ ) aqueous ACS ([ACS $\left.]=1 \times 10^{-6} \mathrm{~mol} \mathrm{~L}^{-1}\right)$; $\left.\mathbf{m}\right)$ mixture of ACS and $\mathrm{SO}_{4}{ }^{2-}$ ions, and $\mathbf{\Delta}$ ) neat salt solution. When used, $\left[\mathrm{SO}_{4}{ }^{2-}\right]=0.3 \mathrm{~mol} \mathrm{~L}^{-1}$. Solid lines represent a linear fit to the experimental data. 


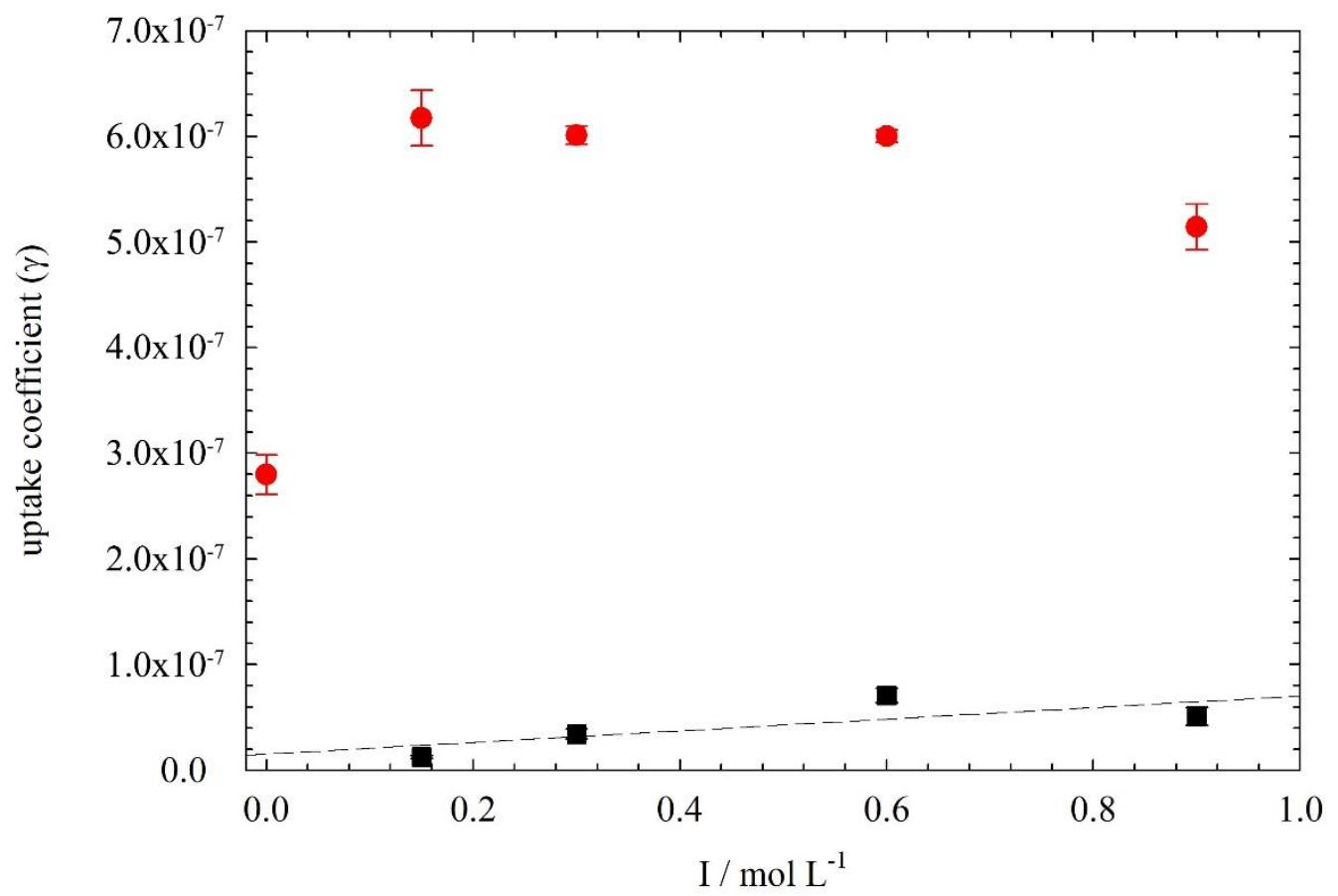

34

Figure S2: The uptake coefficients of $\mathrm{O}_{3}$ as a function of $\mathrm{SO}_{4}{ }^{2-}$ concentrations at $\left[\mathrm{O}_{3}\right]=7.38 \times 10^{12}$ molecules $\mathrm{cm}^{-3}$ (300 ppb) in $\left.\mathbf{~}\right)$ neat salt solution and •) at unadjusted $\mathrm{pH}$ of the solution, containing $\mathrm{ACS},[\mathrm{ACS}]=1 \times 10^{-6} \mathrm{~mol} \mathrm{~L}^{-1}$. In the concentration range of $\mathrm{SO}_{4}{ }^{2-}$ from $0.05 \mathrm{M}$ till $0.3 \mathrm{M}$, $\mathrm{pH}$ values varied from 8.85 till 10.05, respectively. In absence of salt, the $\mathrm{pH}$ value of ACS was 5.76.

39

40

41

42 


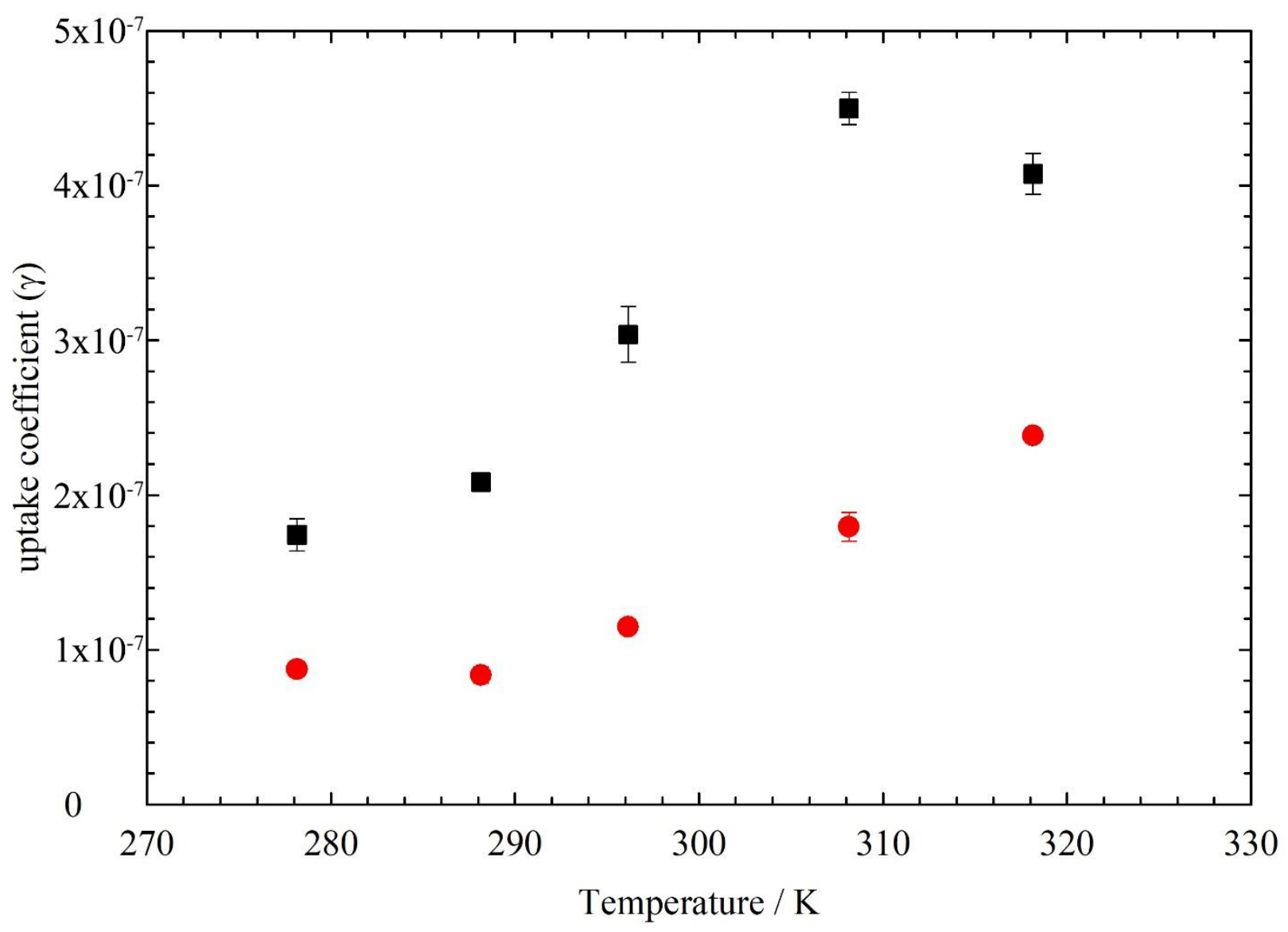

Figure S3: Temperature-dependent uptake coefficients of $\mathrm{O}_{3}$ at $\left[\mathrm{O}_{3}\right]=7.38 \times 10^{12}$ molecules cm${ }^{-3}$ $45(300 \mathrm{ppb}) \bullet)$ in absence of salt and in $\bullet)$ presence of $\mathrm{I}=0.9 \mathrm{M}\left(\left[\mathrm{SO}_{4}{ }^{2-}\right]=0.3 \mathrm{M}\right)$

46

47

48 

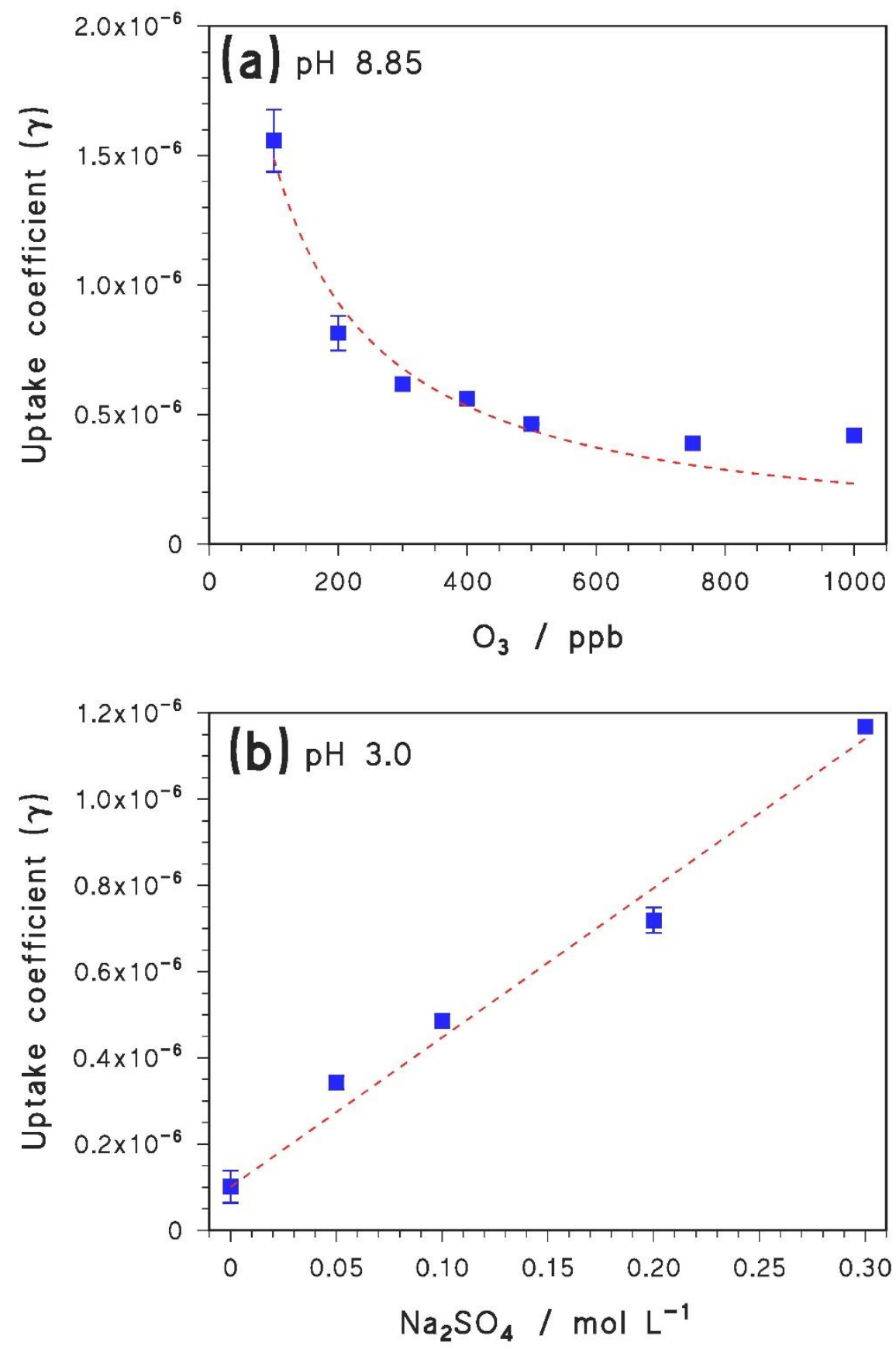

51

52

53

54

55

56

57

58

59

Figure S4. Ability of Eq-12 in the main manuscript to predict the experimental data. (a) $\gamma$ vs. $\left[\mathrm{O}_{3}\right]$, pH 8.85, $c_{\mathrm{Na}_{2} \mathrm{SO}_{4}}=0.05 \mathrm{~mol} \mathrm{~L}^{-1}$. (b) $\gamma$ vs. $c_{\mathrm{Na}_{2} \mathrm{SO}_{4}}, \mathrm{pH} 3.0,\left[\mathrm{O}_{3}\right]=300 \mathrm{ppb}$. In all the cases it was [ACS] $=1 \mu \mathrm{mol} \mathrm{L}{ }^{-1}$. The solid squares represent the experimental data, the dashed curves are the predictions of Eq-12. 
60 Dielectric constant of water, which can be also addressed as a measure of the solvent's polarity, is

61 closely interconnected with the concentrated salt solutions. ${ }^{1}$ Since the electrolyte concentration

62 increases, the dielectric constants of water would consequently start decreasing due to the

63 saturation of the ions in the neighborhood.

64 The dielectric constant of water and the salt concentration follow linear correlation when a solution

65 contains salt concentrations lower than $2 \mathrm{M}$. The linear relationship in the case of sulfate (VI) ions

66 is given by the following form, as suggested by Givon et al. (1963): ${ }^{2}$

$67 \varepsilon=\varepsilon_{\mathrm{w}}+2 \delta^{*}\left[\mathrm{Na}_{2} \mathrm{SO}_{4}\right]$

68 where $\varepsilon$ represents the dielectric constant of a solution, $\varepsilon_{\mathrm{w}}$ corresponds to the dielectric constant of 69 pure water (78.5), $\left[\mathrm{Na}_{2} \mathrm{SO}_{4}\right]$ is the used molar concentration of the salt. $\delta^{*}$, which denotes the mean 70 value of the molar dielectric constant decrement coefficients of the cations and anions of the used 71 electrolyte solution, can be obtained from the Eq-S2:

$72 \quad \delta^{*}=\frac{\left(\delta^{+}+\delta^{-}\right)}{2}$

73 where $\delta^{+}$and $\delta^{-}$are negatively assigned contributions of the electrolytes, presented in used salt (in 74 our example, $\mathrm{Na}^{+}$and $\left.\mathrm{SO}_{4}{ }^{2-}\right)$, respectively. Values of $\delta^{+}\left(\mathrm{Na}^{+}\right)=-10$ and $\delta^{-}\left(\mathrm{SO}_{4}{ }^{2-}\right)=-18$ have been

75 published in the literature. ${ }^{2}$ Table S1 demonstrates calculated decrements of the dielectric 76 constants of water when $\mathrm{SO}_{4}{ }^{2-}$ ions are presented in a solution.

77 High concentrations of electrolytes in a solution significantly alter the solubility of gases. Hence, 78 in the aqueous phase, containing elevated ionic strength conditions such as at the sea-surface 79 microlayer and/or sea-salt aerosol deliquescent particles, dissolution processes of gases differ 80 substantially from those, presented in the dilute atmospheric aqueous-phase. In this case, Herny's 81 law constant of ozone in our case needs to be modified, taking the effect of the ionic strength into 82 account by implementing the Setschenow empirical equation: ${ }^{3}$ 
84 where $\mathrm{H}$ is the Herny's law constant of ozone in the salt solution, $\mathrm{H}_{0}$ is the Henry's law constant

85 of ozone in pure water, $K_{\mathrm{s}}$ is the Setschenow's constant and $\mathrm{c}_{\mathrm{s}}$ is the molar concentration of the 86 used salt $\left(\mathrm{Na}_{2} \mathrm{SO}_{4}\right.$ in this example). The individual effect of the used salt ions and gas on $\mathrm{Ks}$ is 87 combined into the following empirical model: ${ }^{4}$

$88 \quad \mathbf{K}_{\mathbf{s}}=\sum_{\mathbf{i}}\left(\mathbf{h}_{\mathbf{i}}+\mathbf{h}_{\mathbf{G}}\right) \mathbf{x}_{\mathbf{i}}$

89 where $h_{i}$ and $h_{G}$ are the contributions of the used ions and gas. The stoichiometry number of the 90 ion $\mathrm{i}$ in the used salt's chemical formula (in our case, $\mathrm{Na}^{+}=1, \mathrm{SO}_{4}{ }^{2-}=2$ ) is denoted by parameter $91 \mathrm{X}_{\mathrm{i}}$. The temperature dependence of the gas-specific parameter $\mathrm{h}_{\mathrm{G}}$ in Eq-S4 was later suggested by 92 Weisenburger and Schumpe, $(1996),{ }^{5}$ leading to:

$$
\mathbf{h}_{\mathrm{G}}=\mathbf{h}_{\mathrm{G}, 0}+\mathbf{h}_{\mathrm{T}}(\mathrm{T}-298.15 \mathrm{~K})
$$

94 where $h_{\mathrm{G}, 0}$ and $h_{\mathrm{T}}$ are specific parameters for the dissolved gas. The values of $h_{\mathrm{i}}, \mathrm{h}_{\mathrm{G}, 0}$, and $\mathrm{h}_{\mathrm{T}}$ for various ions and gases in a wide temperature range are summarized by Beltran (2004). ${ }^{6}$ The 96 contributions of the ions used in our calculations were $\mathrm{h}_{\mathrm{i}}\left(\mathrm{Na}^{+}\right)=0.1143 \mathrm{~m}^{3} \mathrm{kmol}^{-1}$, and $\mathrm{h}_{\mathrm{i}}\left(\mathrm{SO}_{4}{ }^{2-}\right)$ $97=0.1117 \mathrm{~m}^{3} \mathrm{kmol}^{-1}$ while the gas-specific model parameters for ozone were $\mathrm{h}_{\mathrm{G}, 0}=3.96 \cdot 10^{-3} \mathrm{~m}^{3}$ $98 \mathrm{kmol}^{-1}$ and $\mathrm{h}_{\mathrm{T}}=1.79 \cdot 10^{-3} \mathrm{~m}^{3} \mathrm{kmol}^{-1}$, respectively. The calculated Henry's law constants of ozone 99 at ionic strength conditions are shown in Table S1. 
Table S1: Calculated dielectric constants of water and Henry's law constants of ozone in the presence of different $\mathrm{SO}_{4}{ }^{2-}$ concentrations.

\begin{tabular}{cccc}
\hline$\varepsilon_{\mathrm{W}}$ & {$\left[\mathrm{Na}_{2} \mathrm{SO}_{4}\right]$} & $\begin{array}{c}\mathrm{H}\left(\mathrm{kPa} \mathrm{m}^{3}\right. \\
\left.\mathrm{mol}^{-1}\right)\end{array}$ & $\begin{array}{c}\mathrm{H} \text { (unitless) } \\
\mathrm{RT}\end{array}$ \\
\hline 78.5 & 0 & 9.217 & 0.267 \\
77.1 & $5 \cdot 10^{-2}$ & 9.584 & 0.257 \\
75.7 & $1 \cdot 10^{-1}$ & 9.965 & 0.247 \\
72.9 & $2 \cdot 10^{-1}$ & 10.774 & 0.229 \\
70.1 & $3 \cdot 10^{-1}$ & 11.648 & 0.211 \\
\hline
\end{tabular}

\section{References}

1. Debye, P.; Huckel, E. Zur Theorie der Elektrolyte. Physik. Zeitschr. 1923, 24, 185-206.

2. Givon, M.; Marcus, Y.; Shiloh, M. A Modified Debye Theory of Salting of Nonelectrolytes in Electrolyte Solutions. J. Phys. Chem. 1963, 67, 2495-2497.

3. Setschenow, M. Uber die Konstitution der Salzlosungen auf Grund ihres Verhaltens zu Kohlensaure. Z. Phys. Chem. 1889, 4U, 117-125.

4. Schumpe, A. The estimation of gas solubilities in salt solutions. Chem. Eng. Sci. 1993, 48 (1), 153-158.

5. Weisenberger, S.; Schumpe, A. Estimation of Gas Solubilities in Salt Solutions from 273 K to 363 K. AIChE J. 1996, 42 (1), 298-300.

6. Beltran, F. J. Ozone reaction kinetics for water and wastewater systems; CRC Press LLC: Florida, U.S.A., 2004. 